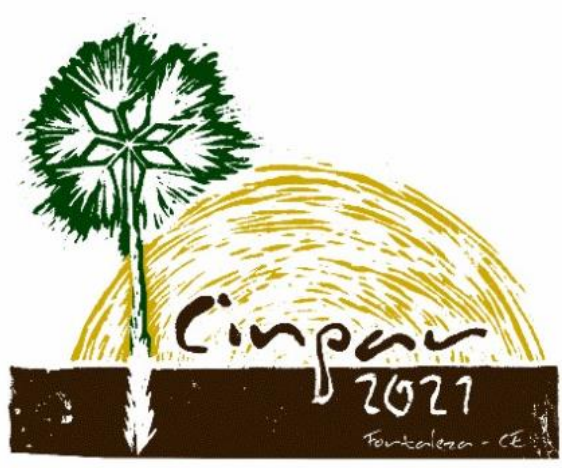

XVII Congresso Internacional sobre Patologia e Reabilitação das Construções

XVII Congreso Internacional sobre Patología y Rehabilitación de las Construcciones

XVII International Conference on Pathology and Constructions Rehabilitation

FORTALEZA (Brasil), 3 a 5 de junho de 2021

https://doi.org/10.4322/CINPAR.2021.156

\title{
Estudo da influência da corrosão por pites nas propriedades mecânicas das barras de Aço CA-50
}

\section{Study of the influence of pitting on the mechanical properties of CA-50 steel bars}

\author{
Késsio Raylen Jerônimo MONTEIRO ${ }^{1}$, Pedro Bonfim SEGOBIA², Jardel Borges BEZERRA ${ }^{3}$, Michelly Queiroz \\ Correia SOUZA ${ }^{4}$, Ítalo Almeida Lopes ${ }^{6}$ e Michele Tereza Marque CARVALHO ${ }^{6}$ \\ ${ }^{1}$ Universidade Federal do Acre, Rio Branco, Brasil, kessio1029@gmail.com \\ ${ }^{2}$ Universidade de Brasília, Brasília, Brasil, engsegobia@gmail.com \\ ${ }^{3}$ Centro Universitário UNINORTE, Rio Branco, Brasil, jardelbezerra124@gmail.com \\ ${ }^{4}$ Centro Universitário UNINORTE, Rio Branco, Brasil, michelly.qcsouza@yahoo.com.br \\ ${ }^{5}$ Centro Universitário UNINORTE, Rio Branco, Brasil, engitalolopes@gmail.com \\ ${ }^{6}$ Universidade de Brasília, Brasília, Brasil, micheletereza@gmail.com
}

\begin{abstract}
Resumo: A corrosão é um fenômeno comum em armaduras de concreto armado. Essa forma de deterioração estrutural impacta numa perda significativa da capacidade de resistência a esforços de tração, o que fragiliza toda a estrutura, tornando-a ineficiente quando submetida às solicitações. Nesse contexto, em virtude da alta utilização do material objeto desta pesquisa e da recorrência do fenômeno deteriorativo supramencionado, neste estudo abordar-se-á a influência da corrosão por pite no aço CA-50. Para tanto, foram empregados métodos de simulação de corrosão em barras de aço de $\varnothing 10$ e $\varnothing 12,5$ milímetros, as quais foram, posteriormente, submetidas a ensaios de resistência à tração. A pluralidade na milimetragem amostrada possibilitou o exame das variações das propriedades mecânicas das barras, quando submetidas a esforços de tração. Ademais, verificou-se uma perda significativa e proporcional à elevação do grau de corrosão em todas as amostras analisadas, o que implicou, principalmente, na perda da capacidade de sofrer deformações plásticas. A presente pesquisa complementa estudos acerca da influência da corrosão por pite, em barras de aço utilizadas no concreto armado, ao aprofundar discussões acerca do seu comportamento do aço sob efeito do processo corrosivo, por meio da análise da corrosão simulada de 1/4 e 1/2 do diâmetro das barras. Evidenciando, desta forma, que a corrosão pode trazer graves prejuízos para as construções e que o cuidado com a armadura é imprescindível para a garantia do bom desempenho da edificação.
\end{abstract}

Palavras-chave: Aço. CA-50. Corrosão. Corrosão por Pite. Propriedades Mecânicas.

Abstract: Corrosion is a common phenomenon in reinforced concrete reinforcement. This form of structural deterioration impacts on a reduction in the capacity to resist traction efforts, which weakens an entire structure, rendering it inefficient when submitted to stresses. In this context, due to the high use of the material object of this research and the recurrence of the aforementioned deteriorating phenomenon, this study will address the influence of pitting corrosion on CA-50 steel. For that, corrosion simulation methods were used on $\varnothing 10$ and $\varnothing 12.5 \mathrm{~mm}$ steel bars, as they were subsequently subjected to tensile strength tests. The plurality in the sampled millimeter made it possible to examine the variations in the mechanical properties of the bars when subjected to tensile stresses. In addition, there was a reduction that was reduced and proportional to the increase in the degree of corrosion in all those analyzed, which implied, mainly, in the loss of the ability to undergo plastic deformations. This research complements complementary studies 
of the influence of pitting corrosion, in steel bars used in reinforced concrete, by deepening the behavior of steel under the effect of the corrosive process, through simulated corrosion analysis of $1 / 4$ and $1 / 2$ the diameter of the bars. This way, evidencing that the corrosion can bring serious damages to the constructions and that the care with the reinforcement is essential for a guarantee of good performance of the building.

Keywords: Steel. CA-50. Corrosion. Pitting. Mechanical Propertie.

\section{Introdução}

Concreto é um material composto essencialmente por cimento, areia, brita e água. A mistura desses elementos permite a formação de uma estrutura que, via de regra, deverá possuir resistência à compressão acima do referencial especificado pelo projetista e das especificações estabelecidas pela Norma Técnica Brasileira n. 0118 (ABNT, 2014), bem como excelente durabilidade. Nesse mesmo sentido expõe Bastos (2006), ao afirmar que o concreto é um material com alta resistência a tensões de compressão.

Contudo, o supra autor alerta sobre a baixa resistência à tração do material, correspondente a aproximadamente $10 \%$ (dez por cento) da sua resistência à compressão. Por essa razão, ainda que o concreto seja um dos materiais mais utilizados na construção civil, perfaz-se a necessidade de adicionar armaduras aos sistemas estruturais elaborados a partir desse insumo, a fim de ampliar a sua resistência mecânica.

À essa estrutura formada da união do concreto e das armaduras é dado o nome de concreto armado. Todavia, Gonçalves (2015) argumenta que é imprescindível haver uma transmissão de força entre o concreto e a armadura para que se tenha constituído o concreto armado. Caso contrário, ter-se-á concreto simples, com a presença de uma armadura sem função resistente, isto é, uma armadura com revestimento de concreto.

Agora, internos à interação concreto-armadura, salienta-se um problema recorrente e grave: a corrosão. Esse fenômeno é o principal causador da deterioração no concreto armado e, por conseguinte, um dos grandes desafios no manuseio de compostos com materiais metálicos. Desafio que, inclusive, excede os limites das áreas estruturais e de construção civil, haja vista a abrangência de sua utilização.

Ademais, Rocha (2015) disserta que um dos principais causadores de patologias no concreto armado é a corrosão, pois afeta a sua durabilidade, vida útil e resistência mecânica, podendo comprometer inteiramente os parâmetros de segurança da construção. Na mesma medida, Gentil (1994) argumenta que todos os materiais metálicos estão sujeitos a sofrer desgaste por meio da corrosão, desde que sejam dadas condições favoráveis para o efeito corrosivo.

Sobre a patologia e meios para combatê-la, a Norma Técnica Brasileira n. 6118, cujo objetivo é estabelecer critérios de proteção e evitar eventuais patologias, aborda reiteradamente que o cobrimento da armadura é essencial e indispensável, pois, conforme o item 7.4.1 da NBR 6118, "[...] a durabilidade das estruturas é altamente dependente das características do concreto e da espessura e qualidade do concreto do cobrimento da armadura" (ABNT, 2014, p. 16).

Nesse sentido, o cobrimento tem função importante na armadura, uma vez que proporciona resistência mecânica, física e química ao concreto armado. Todavia, a má execução do cobrimento pode trazer graves danos, deixando a estrutura vulnerável a ataques corrosivos. Dentre esses, destaca-se a corrosão por pite, caracterizada como um tipo extremamente localizado que culmina na geração de orifícios no material metálico

Inobstante, Silva (2010) define que a corrosão das armaduras é um fenômeno natural, no qual o aço tende a retornar à forma de óxidos de ferro - principais constituintes do minério de ferro. No concreto armado a corrosão é estimulada pela redução do pH do concreto, através da ação do dióxido de carbono em um processo conhecido por carbonatação ou pela presença de cloretos - em exemplo, os cloretos presentes na água do mar que se depositam sobre as superfícies das estruturas do concreto em regiões costeiras.

Outrossim, a corrosão por pite - ou simplesmente pite -, consoante ao supramencionado, define-se pela ocorrência corrosiva localizada e geralmente está relacionada a materiais que formam a camada passiva. Assim, normalmente se verifica o pite através da ruptura desse filme passivo, principalmente qual há a presença de íons de cloretos (FERREIRA et al., 2008). Por fim, acerca dessa camada passiva, compete 
esclarecer que consiste numa fina película passiva aderida à superfície metálica, bem como advém da reação entre os elementos de liga presentes no substrato e de moléculas de água encontradas no ambiente.

Pelo exposto, neste trabalho buscou-se fazer uma exposição acerca das causas de corrosão, com ênfase na corrosão por pite, posto que essa é em uma das principais formas de degradação de metais. Para tanto, foram feitas análises da corrosão por pite nas barras de $\varnothing 10$ e $\varnothing 12.5 \mathrm{~mm}$ com corrosão simulada de D/4 e $\mathrm{D} / 2$, além disso, os resultados foram comparados com a pesquisa de Oliveira (2018) que utilizou o mesmo método de corrosão simulada para $\mathrm{D} / 3$ e $2 \mathrm{D} / 3$ das barras. Desta forma, buscou-se demonstrar a influência da corrosão em armaduras do concreto quando tracionadas; sendo feita, ao final, uma comparação das propriedades mecânicas de acordo com a profundidade dos furos nos corpos de prova.

Por fim, cumpre salientar o exposto por Balestra et al. (2018), o qual indica que independentemente do método de corrosão das barras, seja simulado ou em condições naturais, os estudos apontam para um decrescimento nos valores e desempenho da armadura. Desse modo, foi possível analisar a variação em termos de resistência ao escoamento, limite de resistência e alongamento final das barras de aço submetidas a diferentes graus de corrosão.

\section{Metodologia}

Realizou-se testes em laboratório com o intuito de analisar a influência da corrosão por pite na resistência à tração de barras de aço CA-50 - esse material foi escolhido em razão da sua larga utilização na construção civil. Nessa conjuntura, foram manipuladas barras de $10 \mathrm{~mm}$ e de $12,5 \mathrm{~mm}$ de diâmetro, com as dimensões dos corpos de prova definidas através da Norma Técnica Brasileira n.․7480 de 2007 - NBR 7480 - (ABNT, 2007).

Com relação à corrosão simulada, Balestra et al. (2018) explicam que, para se ter uma diferença na resistência à tração, a armadura precisa perder valores superiores a $20 \%$ da área de sua seção transversal. À vista disso, os corpos de prova, para cada diâmetro, foram divididos da seguinte forma: 1. Barras não corroídas; 2 . Barras cuja corrosão simulada foi de $1 / 4$ do diâmetro (D); e 3. Barras cuja corrosão simulada foi de $1 / 2$ do diâmetro(D). Para a simulação da corrosão, furamos as barras com brocas de $4,5 \mathrm{~mm}$ e $6 \mathrm{~mm}$ de diâmetro para as barras de $\varnothing 10 \mathrm{~mm}$ e $\varnothing 12,5 \mathrm{~mm}$, respectivamente.

As amostras foram submetidas à ensaios para determinação do grau de corrosão, tensão de escoamento, tensão máxima e alongamento final, sendo determinadas as proporções de redução das suas características mecânicas. Posteriormente, os resultados obtidos foram comparados com a pesquisa de Oliveira (2018) que analisou a corrosão simulada para as barras de $\varnothing 10$ e $\varnothing 12.5 \mathrm{~mm}$ com corrosão simulada de D/3 e 2D/3, de forma que possibilitasse compreender o comportamento do aço quando submetido à graus de corrosão distintos.

A Figura 1 mostra a simulação da corrosão por pite ao realizar os furos nas barras de aço. Ao todo, foram amostrados 15 corpos de prova de $\varnothing 10 \mathrm{~mm}$ e 6 corpos de prova de $\varnothing 12,5 \mathrm{~mm}$.

Figura 1 - Furos na armadura simulando a corrosão por pite.

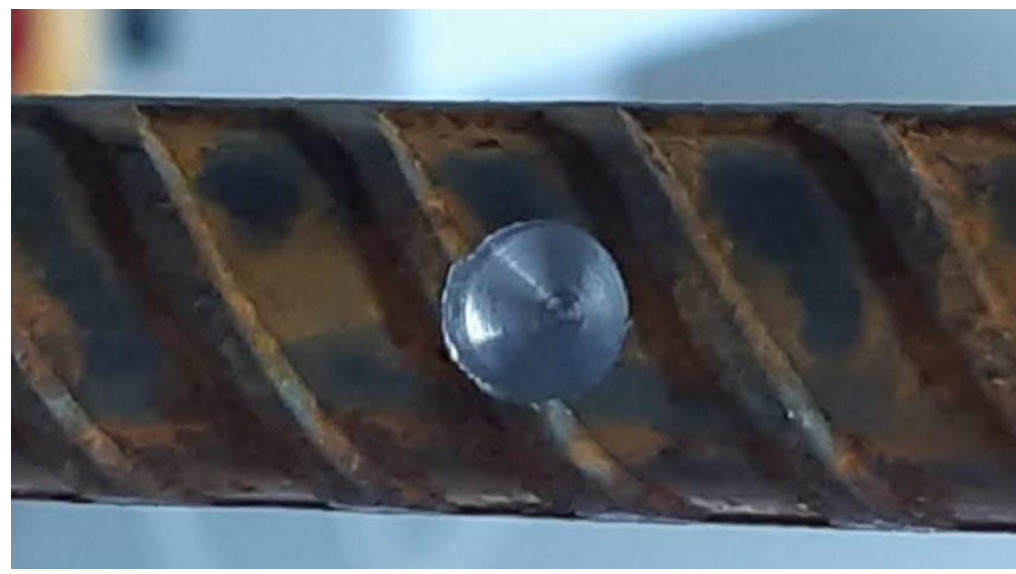


Os ensaios foram realizados no Instituto de Tecnologia Madeira e Móveis Carlos Takashi Sasai - SENAI/AC, mediados pelo equipamento Emic universal $100 \mathrm{kgf}$, que fornece dados de tensão de escoamento, tensão máxima e alongamento máximo.

\section{Resultados e Discussões}

\subsection{Determinação do Grau de Corrosão dos Corpos de Prova (G)}

O grau de corrosão é definido em função da variação de área apresentada pelo corpo de prova (BALESTRA et al., 2018). As barras com furos de $D / 4$ e $D / 2$ foram submetidas a ensaios para determinação do seu grau de corrosão, e posteriormente, foram comparados com o grau de corrosão dos furos de $D / 3$ e 2D/3 encontrados no estudo de Oliveira (2018). O grau de corrosão simulado para as barras se encontra na Tabela 1.

Tabela 1 - Distribuição das amostras de vergalhões

\begin{tabular}{|c|c|c|c|}
\hline $\begin{array}{c}\text { Diâmetro } \\
(\mathbf{m m})\end{array}$ & Furos & $\begin{array}{c}\text { Grau de } \\
\text { corrosão } \\
\text { (\%) }\end{array}$ & Quantidades \\
\hline \multirow{4}{*}{10} & 0 & 0 & 4 \\
\cline { 2 - 4 } & $\mathrm{D} / 4$ & 9,81 & 5 \\
\cline { 2 - 4 } & $\mathrm{D} / 3$ & 15,05 & 6 \\
\cline { 2 - 4 } & $\mathrm{D} / 2$ & 21,8 & 6 \\
\cline { 2 - 4 } & $2 \mathrm{D} / 3$ & 36,27 & 6 \\
\hline \multirow{5}{*}{12,5} & 0 & 0 & 2 \\
\cline { 2 - 4 } & $\mathrm{D} / 4$ & 10,30 & 2 \\
\cline { 2 - 4 } & $\mathrm{D} / 3$ & 14,75 & 6 \\
\cline { 2 - 4 } & $\mathrm{D} / 2$ & 23,51 & 2 \\
\cline { 2 - 4 } & $2 \mathrm{D} / 3$ & 35,03 & 6 \\
\hline
\end{tabular}

A diferença percentual do corpo de prova antes e após a simulação do pite expressa o grau de corrosão, portanto, o mesmo pode ser apresentado em porcentagem (APOSTOLOPOULOS; MICHALOPOULOS; KOUTSOUKOS, 2008).

Quando se comparou a corrosão simulada da barra com furos de $D / 4$ com as de $D / 3, D / 2$ e 2D/3, verificouse que os valores do grau de corrosão crescem de acordo com o aumento da profundidade dos furos, conforme apresentado na Tabela 2, o que já era esperado de acordo com o estudo de Oliveira (2018).

Tabela 2 - Comparativo do diâmetro dos furos e grau de corrosão para as barras

\begin{tabular}{|c|c|c|c|}
\hline & $\mathrm{D} / 4-\mathrm{D} / 3$ & $\mathrm{D} / 4-\mathrm{D} / 2$ & $\mathrm{D} / 4-2 \mathrm{D} / 3$ \\
\hline Profundidade dos furos & $33,3 \%$ & $100,0 \%$ & $166,7 \%$ \\
\hline $\begin{array}{c}\text { Grau de Corrosão } \\
\text { Das barras de } \varnothing 10 \mathrm{~mm}\end{array}$ & $53 \%$ & $122 \%$ & $270 \%$ \\
\hline $\begin{array}{c}\text { Grau de Corrosão } \\
\text { Das barras de } \varnothing 12,5 \mathrm{~mm}\end{array}$ & $43 \%$ & $128 \%$ & $240 \%$ \\
\hline
\end{tabular}

\subsection{Tensão de Escoamento $\left(f_{y}\right)$}

A tensão de escoamento apresentou um comportamento semelhante para os diâmetros, sendo observada uma diminuição conforme o grau de corrosão aumentava. Para a propriedade de tensão de escoamento considerou-se que as barras deveriam apresentar resistência característica mínima de $500 \mathrm{Mpa}$, conforme exigido pela NBR 7480 (ABNT, 2007).

Para as barras de $\varnothing 10 \mathrm{~mm}$, todas as amostras sem corrosão apresentaram valores superiores ao normativo, porém as amostras com furos de D/4 e D/2 apresentaram uma redução de 7,98\% (sete inteiros e noventa e oito centésimos por cento) e de $24,70 \%$ (vinte e quatro inteiros e setenta centésimos por cento) da sua tensão de escoamento, não atingindo, pois, os valores mínimos estabelecidos. 
No que tange às barras de $\varnothing 12,5 \mathrm{~mm}$, as amostras sem corrosão apresentaram valores superiores ao normativo. Além disso, apesar de as barras com furos de $D / 4$ e $D / 2$ apresentarem uma perda de $6,44 \%$ (seis inteiros e quarenta e quatro centésimos por cento) e de 7,06\% (sete inteiros e seis centésimos por cento) em sua resistência, atingiram valores acima do mínimo estabelecidos pela norma.

Tabela 3 - Tensões médias de escoamento das barras

\begin{tabular}{|c|c|c|c|}
\hline \multirow{2}{*}{$\mathbf{D}(\mathbf{m m})$} & $\begin{array}{c}\text { SEM } \\
\text { CORROSÃO }\end{array}$ & $\mathrm{D} / 4$ & $\mathrm{D} / 2$ \\
\cline { 2 - 4 } & $\begin{array}{c}\bar{x} \\
(\mathrm{Mpa})\end{array}$ & $\begin{array}{c}\bar{x} \\
(\mathrm{Mpa})\end{array}$ & $\begin{array}{c}\bar{x} \\
(\mathrm{Mpa})\end{array}$ \\
\hline $\mathbf{1 0}$ & 514,81 & 473,75 & 387,67 \\
\hline $\mathbf{1 2 , 5}$ & 545,4 & 510,29 & 506,87 \\
\hline
\end{tabular}

Ante ao exposto, concluiu-se que as maiores perdas de resistências estão associadas às barras de $\emptyset 10 \mathrm{~mm}$ com furos de $D / 2$, ou seja, a corrosão por pites é verificada como mais agressiva em armaduras de menores diâmetros.

Pode-se verificar também uma tendência à redução dos valores de tensão de escoamento das barras conforme o aumento da profundidade dos furos independente do diâmetro das barras. Esse fato também foi verificado no estudo de Oliveira (2018), na qual as barras com furos de maiores profundidades apresentaram as maiores reduções em seus valores médios.

Observou-se ainda que as barras utilizadas neste estudo apresentaram tensões médias de escoamentos menores nas barras sem corrosão em relação ao estudo de Oliveira (2018), o que pode ter colaborado para o não atendimento aos parâmetros normativos, tal situação pode ser explicada devido características intrínsecas às barras, devendo-se aprofundar os estudos sobre a composição dos materiais para complemento do estudo.

\subsection{Tensão Máxima $\left(f_{s t}\right)$}

O limite mínimo de resistência exigido pela NBR 7480 (ABNT, 2007) é de 540 Mpa para aços CA-50. Desta forma, conforme apresentado na Tabela 4, todos as amostras sem corrosão apresentaram resultados acima do normativo.

Em contrapartida, as barras de $\varnothing 10 \mathrm{~mm}$, com furos de $\mathrm{D} / 4$ e de $\mathrm{D} / 2$, tiveram uma perda de $19,63 \%$ (dezenove inteiros e sessenta e três centésimos por cento) e de 35,94\% (trinta e cinco inteiros e noventa e quatro centésimos por cento) da sua resistência, respectivamente. Consequentemente, após os efeitos corrosivos, em ambos os casos, o aço se tornou ineficiente quando submetido ao tracionamento, nessas respectivas proporções.

Quanto às barras de $\varnothing 12,5 \mathrm{~mm}$, as com furos de $\mathrm{D} / 4$ apresentaram valores acima dos exigidos pela norma, isto é, apenas apenas as amostras com $\mathrm{D} / 2$ não atenderam aos padrões normativos e demonstraram uma perda, respectivamente, de 5,29\% (cinco inteiros e vinte e nove centésimos por cento) e de $14,60 \%$ (quatorze inteiros e sessenta centésimos por cento) da sua resistência.

Tabela 4 - Valores médios de tensões máximas das barras

\begin{tabular}{|c|c|c|c|}
\hline \multirow{2}{*}{$\mathbf{D}(\mathbf{m m})$} & $\begin{array}{c}\text { SEM } \\
\text { CORROSÃO }\end{array}$ & $\mathrm{D} / 4$ & $\mathrm{D} / 2$ \\
\cline { 2 - 4 } & $\begin{array}{c}\bar{x} \\
(\mathrm{Mpa})\end{array}$ & $\begin{array}{c}\bar{x} \\
(\mathrm{Mpa})\end{array}$ & $\begin{array}{c}\bar{x} \\
(\mathrm{Mpa})\end{array}$ \\
\hline $\mathbf{1 0}$ & 606,67 & 487,58 & 388,65 \\
\hline $\mathbf{1 2 , 5}$ & 615,9 & 583,29 & 525,93 \\
\hline
\end{tabular}

Nenhuma das amostras com corrosão simulada de D/2 apresentou plasticidade. Dessa maneira, sua ruptura ocorreu no momento em que a força aplicada levou os vergalhões a atingirem sua resistência máxima ao escoamento. Nos vergalhões com D/4, dois corpos de prova também não apresentaram resistência plástica; evento que se observa, via de regra, quando o material está muito frágil. Além disso, a redução nos valores 
da tensão máxima já era esperada, uma vez que no estudo de Oliveira (2018) nenhuma das barras submetidas a corrosão simuladas atenderam aos parâmetros normativos.

\subsection{Alongamento Final}

As amostram também foram submetidas à ensaios para determinação da redução do seu alongamento final, conforme apresentado na Tabela 5.

Tabela 5 - Perda da capacidade de alongamento

\begin{tabular}{|c|c|c|}
\hline \multirow{2}{*}{$\mathbf{D}(\mathbf{m m})$} & Diâmetro & Redução (\%) \\
\hline \multirow{2}{*}{10} & $1 / 4 \mathrm{D}$ & 85,04 \\
\cline { 2 - 3 } & $1 / 2 \mathrm{D}$ & 76,49 \\
\hline \multirow{2}{*}{12,5} & $1 / 4 \mathrm{D}$ & 14,28 \\
\cline { 2 - 3 } & $1 / 2 \mathrm{D}$ & 57,14 \\
\hline
\end{tabular}

É possível inferir que quanto menor for o diâmetro das barras de aço CA-50, menor será sua capacidade de alongamento quando submetidos a efeitos corrosivos. Essa perda na capacidade de deformação, encontrada nas armaduras de aço CA-50, pode estar relacionada ao fato de que quando se eleva o grau de corrosão, ocorre a ruptura da armadura antes mesmo do material entrar na fase de deformação plástica.

A hipótese encontra amparo no concluído por Oliveira (2018) em seu estudo, no qual contatou-se que a corrosão acarreta a redução das propriedades mecânicas das armaduras, inclusive o alongamento final. Essa observação justifica, em parte, o motivo de os corpos de prova terem se rompido exatamente na tensão elástica máxima.

\section{Conclusões}

Dentre as propriedades analisadas, a perda de capacidade de se alongar do aço, quando submetido a esforços de tração, foi a que apresentou resultados mais temerários num contexto interno ao uso do material na construção civil. Isso porque a perda da capacidade de alongamento afeta diretamente a resistência máxima do material, o que pode gerar a perda da capacidade de sofrer deformação plástica.

A tensão de escoamento demonstrou expressivos declínios nos valores quando analisada a resistência das amostras, na proporção em que os graus de corrosões simulados aumentavam. Além disso, restou comprovado que o aço de $\varnothing 10 \mathrm{~mm}$ não obteve resultados satisfatórios quando submetido à corrosão mínima de $\mathrm{D} / 2$. Não obstante, as bitolas de $\varnothing 12,5 \mathrm{~mm}$, mesmo com $\mathrm{D} / 2$ de corrosão, ainda apresentaram resistência aceitável. Por conseguinte, demonstrou-se que a capacidade de resistência ao escoamento do aço, quando submetido à corrosão, aumenta proporcionalmente ao aumento do diâmetro das barras.

A tensão máxima apresentou comportamento similar à tensão ao escoamento, todavia sua capacidade de escoamento plástico foi bastante reduzida, bem como, em alguns casos, não houve ruptura quando o material atingiu sua fase elástica. A hipótese levantada é de que essa reação ocorra em decorrência da perda de capacidade do material de sofrer alongamento.

Destarte, é possivel concluir que quanto maior for o grau de agresividade da corrosão, maior será a perda de resistência ao escoamento. Apesar disso, as barras com maiores diâmetros acabam, mesmo com maior perda de sua área, apresentando uma redução média menor em resistência ao escoamento. Isso indica que os efeitos da corrosão são mais severos em barras de menores diâmetros sob a perspectiva da resistência ao escoamento.

\section{Referências Bibliográficas}

APOSTOLOPOULOS, C.A, MICHALOPOULOS, D., KOUTSOUKOS, P. (2008). The corrosioneffects on the structural integrity of reinforcing steel. Journal of Materials and Engineering and Performance, v.17, n. 4, p. 506-516, Ago. 2008. 
ASSOCIAÇÃO BRASILEIRA DE NORMAS TÉCNICAS (2014). NBR 6118: Projeto de estruturas de concreto: Procedimento. Rio de Janeiro, 2014.

ASSOCIAÇÃO BRASILEIRA DE NORMAS TÉCNICAS (2007). NBR ISSO 7480: Aço Destinado a armaduras para estruturas de concreto armado: Especificações. Rio de Janeiro, 2007.

BALESTRA, C. E. T. LIMA, M. G. MENDES, A. Z. MEDEIROS-JUNIOR, R. A. (2018). Efeito do grau de corrosão em propriedades mecânicas de armaduras enterradas por 60 anos. Revista IBRACON Estrut. Mater., v. 11, n. 3. São Paulo, maio/jun., 2018.

BASTOS P. S. S. (2006). Apostila: Fundamentos do concreto armado. Departamento de Engenharia Civil Universidade Estadual Paulista, Bauru, 2006.

FERREIRA, A., GARCIA, V., NETO, A., BASTOS, I. (2008). Modelagem Computacional da Corrosão por Pites em Aço Inoxidável com Inclusões de MnS. Corros. Prot. Mater. [online]. 2008, v. 27, n. 2, pp. 54-62. ISSN 08701164.

GENTIL, V. Corrosão. 3 edição. Rio de Janeiro: Guanabara dois, 1994.

GONÇALVES, E. A. B. (2015). Estudo de patologias e suas causas nas estruturas de concreto armado de obras de edificações. Trabalho de Conclusão de Curso - Universidade Federal do Rio de Janeiro. Rio de Janeiro, 2015.

OLIVEIRA, Isabelle C. De (2018). Estudo da influência da simulação de corrosão por pites nas propriedades mecânicas de armaduras submetidas à tração. 2018. 79 f. Trabalho de Conclusão de Curso - Graduação em Engenharia Civil, Universidade Tecnológica Federal do Paraná. Toledo, 2018.

ROCHA, B. S. (2015). Manifestações patológicas e avaliação de estruturas de concreto armado. Monografia, Universidade Federal de Minas Gerais. Belo Horizonte, 2015.

SILVA, Djalma Ribeiro (2010). Estudo de inibidores de corrosão em concreto armado, visando a melhoria na sua durabilidade. Tese (Doutorado em Ciências e Engenharia de Materiais), Universidade Federal do Rio Grande do Norte, Programa de Pós-Graduação em Ciências e Engenharia de materiais. 